\title{
PERSONAL CONTROL AND HEALTH PROMOTION
}

\author{
Christopher Peterson ${ }^{1}$ and Albert J. Stunkard ${ }^{2}$ \\ 'Department of Psychology, University of Michigan, 580 Union Drive, Ann Arbor, MI 48109 and \\ ${ }^{2}$ Department of Psychiatry, University of Pennsylvania, Philadelphia, PA 19104, U.S.A.
}

\begin{abstract}
Personal control is an individual's belief about the degree that he or she can bring about good events and avoid bad events. High personal control is associated with intellectual, emotional, behavioral, and physiological vigor in the face of challenging situations and events; low personal control is associated with maladaptive passivity and poor morale. In this paper, we sketch the roots of the personal control concept and propose a composite theory of personal control. Then we apply this composite theory to health promotion, a field defined by a cluster of techniques without a unifying theory. We believe that the personal control concept can be the cornerstone for a theory of health promotion.
\end{abstract}

Key words - personal control, health promotion

\section{INTRODUCTION}

In this paper, we discuss the potential value of the concept of personal control for the field of health promotion. Both the review and the discussion are timely. On the one hand, theories of personal control are proliferating within psychology. On the other hand, the large and burgeoning field of health promotion has developed on an almost exclusively empirical basis, with no central or unifying theory. Theoretical issues have played but a minor role in the development of the field [1]. Strong, relevant theory could be of immeasurable value to further progress of health promotion.

Personal control consists of a person's beliefs about how well he or she can bring about good events and avoid bad events. This concept has far-reaching consequences. Current psychological theory and research suggest that such beliefs do more than simply predict future behavior; they determine it [2]. Personal control may underlie all forms of behavior change, including those required for the promotion of health.

This review takes as its starting point the striking similarity among popular theories of personal control. We will present a composite theory that encompasses the underlying themes of the constituent theories. Then we will explain the pertinence of this theory, at both the individual and collective levels, to health promotion. It is our belief that this theory can become the cornerstone of a general theory of health promotion.

\section{HISTORICAL BACKGROUND}

Personal control is a theory for the 1980s, but its origins go back more than half a century. Within the social sciences, concepts akin to personal control have been proposed throughout the years, often in response to overly mechanistic theories of human behavior. Concern with personal control has usually arisen as a correction to theories which view people as passive organisms whose behavior is strictly deter-

This paper is based on a report provided to the Henry $J$. Kaiser Foundation. mined, whether by biological, environmental, and/or social forces.

Some of the earliest cognates of personal control are found as reactions to the first psychoanalytic theories. Where Frcud saw antagonism between people and their world (i.e. between the id and the ego), later theorists proposed a 'conflict-free sphere of the ego' which represented the functions of mastery [3-8].

Social psychologist Kurt Lewin similarly argued that people do more than just react to the world [9]. They also strive to control it. In his analysis of naive psychology, Fritz Heider discerned an analogous notion, which he called the can of behavior [10, p. 84]. It "refers to a relatively stable relationship between the person and the environment... it allows the person to ask and answer such questions as, 'Will I be able to do the task again?" "

Early concern with control was not limited to psychology. Social theorists like Durkheim and Marx suggested that an entire society could be characterized in terms of the efficacy (or inefficacy) of its members. The converse of efficacy concepts like anomie and alienation are still present in sociology and political science $[11,12]$ and have found their way into psychology [13].

Particularly notable is Robert White's classic paper on competence [14]. Dissatisfied with drive-reduction theories of motivation, White marshalled evidence that people are motivated to interact effectively with their environment. He termed this capability competence. The motivation to be competent he called effectance motivation. The experience of effective interaction with the world he called a feeling of efficacy.

Even this brief overview of the intellectual precursors of personal control shows that theorists throughout this century have been concerned with people's mastery of the environment. Mastery was usually conceived as a need or a drive. If this need were satisfied, then one would effectively cope with the world. If not, then one would function poorly.

In the 1960s, an important technological innovation had sweeping consequences for theories of personal control. The computer revolution ushered in a host of cognitive theories to replace earlier formulations that had ignored the mental life of people [15]. 
Cognitive theories drew on the terminology of information processing instead of needs and drives or stimuli and responses. Theories of personal control were not lost in this reformulation; they were simply recast in the new language.

Effectance changed from a motive, with biological connotations, to an idea (belief, expectation, attribution, perception). Where the early theorists emphasized drives to master the environment, the new generation of theorists spoke of beliefs about whether or not this could be done. This change was not just semantic. Two effects of transforming effectance motivation into a belief have been far-reaching.

First, researchers turned their attention to specific aspects of the person. Motivation may be general, but beliefs are always specific. And contemporary psy. chology holds that prediction is greatly improved by specificity $[16,17]$.

Second, the cognitive revolution also directed researchers to the environment and the way that a person interacts with it. Whereas motives reside only within a person, beliefs span both the person and his world. Again, modern psychology holds that prediction is greatly enhanced by simultaneously taking into account both personal and situational characteristics [18-20].

The consequences of people's beliefs about control have been examined in a variety of paradigms since the $1960 \mathrm{~s}$. Control has been variously operationalized as choice, predictability, and contingency. However control is conceived, research results showed that it is usually beneficial [21]. It is associated with superior coping and adaptation, with positive mental and physical health, with optimism and vigor. Surprisingly, people may not need to actually exercise control in order to benefit from it. Studies have shown that the perception of control is often enough to reduce stress, increase motivation, and encourage performance [22-24].

\section{A COMPOSITE THEORY OF PERSONAL CONTROL}

Much of the work on personal control has taken place within social psychology, reflecting a concern with the social environment in fostering or inhibiting personal control. However, theories of personal control also show the influence of personality psychology (in conceiving personal control as an individual difference) and of clinical psychology (in designing interventions for disorders of personal control).

Theories of personal control have been proposed within each of these fields. A number of these theories currently compete in the professional literature [25-40]. Theorists often distinguish their favored concepts from those of the others. Such distinctions are valuable in encouraging more precise use of terms. Nevertheless, another strategy is also valuable: rather than making distinctions, look for what is common. If one takes a look, striking similarities appear.

Impressed with what is common to these theories, we propose a composite theory of personal control characterized by the following family resemblance:

1. personal control is one of the most important ways in which people differ from each other;
2. it resides in the transaction between the person and the world; it is neither just a disposition nor just a characteristic of the environment;

3. personal control is a belief about how one can interact with the world; it may take the form of believing that one can effect actual outcomes, choose among them, cope with their consequences, and/or understand them;

4. personal control can be measured by selfreport questionnaires;

5 . in a responsive environment, personal control is desirable; it encourages intellectual, emotional, behavioral, and physiological vigor in the face of challenge;

6. personal control is catalyzed by novel and challenging events; similarly, lack of personal control becomes salient in the face of overwhelming aversive events;

7. personal control can be thwarted by failure and encouraged by success, although it does not bear a one-to-one relationship to past patterns of success and failure.

Personal control is thus both a cause and a consequence of the way people respond to their environment.

Because the individual theories can be combined does not mean that they should be discarded. The composite theory presented here is only as reasonable as its components. However, a generic theory has certain merits. It brings order to a cluttered field. Questions that transcend specific research traditions can be identified. Applications can be derived.

Our theory may strike some as more of a framework than a theory proper, but we think this is a misleading impression. Our generic account of personal control specifies constructs, their interrelations, and their empirical consequences. It is consistent with past research and points the way for future investigations. Our composite theory appears stark only because it is stripped of the highly technical terminology with which the compont theories are phrased. It fares none the worse conceptually for being stated so plainly.

\section{REMAINING QUESTIONS}

Our composite is not finished business. Although the empirical support for the constituent theories counts toward its validity, research has yet to test a gencric account of personal control. Further, there are areas of legitimate controversy within and between the contemporary theories that the composite theory does not resolve. Some issues await answers.

\section{Is personal control general or specific?}

In keeping with the contemporary distrust of broad personality dispositions [4I], few of the contemporary theories of personal control suggest that a person is simply across-the-board efficacious or not. Specificity is built into all the theories since beliefs about mastery involve control over a specific situation. Thus, researchers have studied locus of control as it involves academic outcomes, health outcomes, or social outcomes [42].

Personal control broadens our understanding of 
changes in actions that encompass both specific behaviors and diffuse lifestyles, as long as the tradeoff between accuracy and scope is appreciated. The answer to the question about the generality of personal control depends on one's purpose.

\section{How is personal control malleable?}

Granted the desirability of control, people's predisposition to achieve control, and the reciprocal relationship of control and success, understanding how to achieve personal control is surprisingly elusive. In a way, personal control is like love: easier to stifle than to foster. The present literature provides no answers as to why this is the case, although Langer's notion of mindfulness gives a clue [36]. She believes that personal control is activated only in the course of meeting challenges. Everyday successes do not strengthen one's sense of control, although everyday failures weaken it.

Theories of personal control do not always take into account the actual responsiveness of the environment. It is often assumed that responsive environments are the rule and unresponsive environments the exception, but no census of behavioral settings has been taken. Perhaps a pessimistic view is closer to the facts. Everyday life is filled with hassles : mundane yet annoying occurrences that are uncontrollabletelephone calls in the middle of the night, scraped fenders in a parking lot, letters lost by the post office, broken fingernails, stuck zippers, and so on [43]. Perhaps those daily hassles take their toll on personal control.

\section{Is personal control motivated?}

The idea of personal control originated in motivational theories, so there is a certain irony in the current debate as to whether people are motivated to achieve personal control. White argued that effectance motivation is an inherent property of all people, even of animals [14], but Rodin, Rennert and Solomon question whether personal control is motivated at all [44]. There is no question that personal control can be stressful. In making a choice, one risks being wrong. A burden of responsibility follows failed attempts, and some people may try to avoid the exercise of personal control. Decades ago, Erich Fromm in Escape from Freedom argued that social movements like fascism attract people precisely because they deny them freedom to choose-and thereby the possibility of being wrong [45].

The question of motivation depends upon what one feels obliged to explain: the presence or absence of personal control. Seligman compares this debate to the contrast between the astronomy of Galileo and that of Aristotle [28]. Are heavenly bodies inherently in motion? If so, then one need only explain why they cease to move. Or are heavenly bodies naturally at rest? Then one must explain why they move. However this argument is resolved, it is clear that in certain situations, personal control is sought because it is instrumental to do so. In other situations, personal control is not sought because it is futile to do so. Whether or not personal control is motivated, it is sensitive to the response-outcome texture of particular environments.

\section{Is personal control arrived at rationally?}

Early cognitive theories used an informationprocessing metaphor that stresses the rationality of behavior [15]. 'Man as scientist' gathered and utilized information according to normative principles $[10,25,46,47]$. Before long, however, it became apparent that human cognition is not strictly rational. Instead, it is affected by needs and emotions, and governed not by normative principles but by cognitive shortcuts and biases [48].

Various theorists have elaborated on the notion that personal control may be illusory [49-52]. Regardless, a sense of personal control is associated with health and happiness, while its absence-even if realistic-is not [40]. For instance, DeMonbreun and Craighead studied the response of depressed and nondepressed people to experimentally-induced successes and failures [53]. The distinction between depressed and nondepressed people is not in their experience of success, which both recognize. Rather, they are distinguished by their experience of failure: depressed people acknowledge it and recall it accurately, while the nondepressed do not!

The rationality or irrationality of personal control will be understood as researchers turn their attention to the process of how information relevant to personal control is obtained and used. Most theories have only stretched the surface here, suggesting that there are individual differences in the way that people react to events that may indicate personal control.

\section{What is the best way to assess personal control?}

A critical element in the psychology of personal control is its assessment. Personal control has generally been assessed by self-report questionnaires or inferred from distant but ostensibly pertinent consequences. There is no problem in the use of questionnaires, or in distant inference, but exclusive reliance upon a single procedure should be avoided. A multimethod approach to the assessment of personal control greatly increases its power and should be undertaken more frequently [54].

\section{How is personal control related to the larger social context?}

With the exception of Bandura, personal control theorists have focused almost exclusively on the individual [55]. A full account of personal control should place the individual in his or social setting. Furthermore, it appears to us that not only individuals but also groups of people may possess a sense of control. As Rappaport observed, "control is one of the few variables in the social sciences that may be shown to have a consistent relationship which ties research across levels of analysis" [56, p. 1].

A major strength of the concept of personal control is the possibility of using it at the social as well as the individual level of analysis. It may be possible to characterize groups as well as individuals as more or less efficacious with respect to a given goal. For example, there are groups with a strong masteryorientation which believe that through their efforts, they can achieve group goals. Other groups have a weak mastery-orientation. We propose that this sense of collective control can result not only in greater 
accomplishment on the part of the group, but by analogy to the findings on personal control, can also lead to higher morale, greater perseverance in the face of failure, greater tolerance of interruption and turnover, and better physical health.

We envision collective control as a norm-or shared belief-about the way that the group works, what it is that the group can and cannot accomplish by what actions. We expect that one problem of groups within a bureaucracy results from a low sense of collective efficacy, when group members can see no connection between what they do and the eventual products of their activity. In such circumstances, workers may become listless, or begin to define their own-more proximal-goals and ignore the organization's goals.

Cultural norms concerning collective control are perhaps the single most important determinant of personal control. The individual bias of most theories of personal control causes this determinant to be overlooked, but as we turn to how our composite theory applies to health promotion, the importance of shared beliefs about control becomes clear.

\section{PERSONAL CONTROL AND HEALTH}

A growing body of research suggests that belief in one's competence is closely tied to physical wellbeing, while a belief that one is helpless is associated with mortality and morbidity. Positive correlations between personal control and health have been found by a large number of investigators in different fields $[39,40,57-66]$. We do not intend to review these studies here, because the link between personal control and health is well-established. Our concern instead is with the theoretical implications of this correlation, particularly with regard to health promotion.

What accounts for these correlations between personal control and health? Various mechanisms are plausible [67]. First, people with high personal control are more likely to have a healthy lifestyle. Second, they are more likely to seek and follow medical advice when ill. Third, they avoid life crises to a greater degree than those with low personal control. Fourth, they are more skilled at coping with life crises that do occur. Fifth, they garner more social support, which in turn buffers them against illness [68]. Sixth, and most intriguing, they may have more competent immune systems.

Research has yet to determine the extent to which these different mechanisms influence health, and there are many obstacles to such an effort. Personal control is only one of many factors determining health and illness, and high correlations between control and health outcomes are hardly to be expected. It is not surprising that correlations between personal control and health do not always exist, and when they do, they tend to be modest. Furthermore, some measures of personal control used in past research have lacked specificity. Finally, self-report measures of illness and those that rely on self-referral for medical care must be used with caution, since personal control significantly affects one's perception and reporting of physical well-being, giving rise to contaminated outcome measures. (To complicate matters further, people's perceptions of health-even when at odds with 'objective' medical tests-may indeed predict subsequent health and illness $[69,70]$.)

Despite these uncertainties, results linking personal control and health are encouraging. There is abundant evidence that personal control-if not the mediator of behavioral change-is one of the most important factors determining whether or not an individual can alter self-defeating habits [34], including the modification of risk factors for illness [71]. O'Leary provides a thorough review of research on risk factor reduction [72]. She concludes that personal control is related to a variety of health interventions:

The evidence taken as a whole is consistent in showing that people's perceptions of their efficacy are related to different forms of health behavior. In the realm of substance abuse, perceived self-regulatory efficacy is a reliable predictor both of who will relapse and the circumstances of each person's first slip. Strong percepts of efficacy to manage pain increase pain tolerance... (Personal control over)... eating and weight predicts who will succeed in overcoming eating disorders. Recovery from the severe trauma of myocardial infarction is tremendously facilitated by the enhancement of the parents' and the spouses' judgments of their physical and cardiac capabilities. And self-efficacy to affect one's own health increases adherence to medical regimens [72, pp. 448-449].

O'Leary goes on to suggest that ideas of personal control may be generally useful in designing interventions to promote health.

\section{PERSONAL CONTROL AND HEALTH PROMOTION}

Missing in the literature is a comprehensive statement regarding how control pertains to health promotion. We attempt such a statement here. Health promotion is currently a field without a theory. It has goals and technologies, but only common sense relates the two [1]. Health promotion as a scientific endeavor has been hampered by this dearth of theory, and our composite theory of personal control may fill this gap.

So far we have referred to health promotion as a unitary concept. This practice has been justified in the past, since health promotion admits to a simple characterization:

The fundamental hypothesis of health promotion is that modification of behavior to better fit practices associated with health and longevity will in fact increase health and longevity $[73$, p. 6].

But in recent years, the characterization of health promotion has become more complex. Health promotion attempts to change behaviors that correlate with morbidity and mortality. A number have now been identified, the most important being poor nutrition, overeating, physical inactivity, use of alcohol, drugs and tobacco, stress, insufficient sleep, and failure to adhere to therapeutic regimes of various types [74, 75].

These risk factors cannot be attacked as a whole and indeed, modification of any two factors may require altogether different strategies. The targetted behaviors vary from circumscribed (as in smoking) to diffuse (as in stress), and the benefits vary from immediate (as in sleep) to distant (as in tobacco use). Risk factors also vary in the degree to which they are 
embedded in the larger culture and in the cost for change.

Clearly, health promotion is a heterogeneous activity. How can the field be ordered? There are at least three parameters of health promotion to consider: the risk factors discussed above; the objective; and the population.

The objective of health promotion is the criterion used to judge an intervention: decreased mortality; decreased morbidity; decreased risk; altered behavior; increased participation; improved morale; or decreased turnover or absenteeism. A health promotion project may attempt to affect all of these, but one or two criteria are usually the most critical and serve as the objective(s).

The population whose health is of concern exists at one of several social levels: individual people, who are advised by a physician to cut back on desserts; families, which make a collective decision to bicycle together twice a week; social networks, like friends or neighborhoods, which unite to control drug use by local children; organizations, like work sites or schools, which decide to banish smoking around others; or society as a whole, which is influenced by public service announcements about the control of hypertension. The techniques for producing change at one of these levels may be quite different from those for producing change at the others.

When we refer to health promotion, we mean for a given risk factor, for a particular objective, and for a particular population. This complexity has contributed to the aforementioned dearth of theory in health promotion. The technical expertise needed to mount a weight-reduction campaign at a work site is so different from that required to combat drug use among high school students that professionals working at these two projects may have little to say to each other. The problems they face and the details of their work are so different that theoretical concerns with health promotion as a whole are not readily raised.

The ideas of personal and collective control may provide a broader picture of health promotion by specifying the links between behavior and health [76]. Whatever the risk factor, objective, or population, modification of a particular behavior involves control. Although techniques of modification differ markedly across health promotion interventions, they can be interpreted in terms of control. In fact, our composite theory of control may help to explain why and how interventions are different.

Personal control pertains to health and illness because it underlies coping in the broadest sense. In contrast to people with diminished personal control, people with strong personal control respond better to challenges. They are more likely to avoid crisis in the first place, and to seek out good advice and comply with it. They are good problem solvers, and they are optimists. Those concerned with health promotion should find much of value here. The ideas of personal and collective control can contribute to health promotion in at least ten ways:

(1) Personal control helps us understand why health promotion is successful in certain cases.

Any of a number of different interventions have succeeded in modifying risk factors [77]. Personal control may be the common element in these effects. Interventions may work because they enhance the sense of control of the population in question, or because they tap into an already-existing sense of control over the behaviors to be changed.

Personal control helps explain an intriguing puzzle in the health promotion field: interventions targeted at one risk factor may also reduce other risk factors [78]. As an individual masters the behaviors needed to reduce one risk factor, his personal control over related behaviors may also be enhanced, and he may reduce other risk factors without specific interventions urging him to do so.

Of course, the opposite can occur. For instance, people who stop smoking usually gain weight. In addition to the metabolic basis for this sequence is a self-fulfilling prophecy in which the person who says no to cigarettes says yes to snacks. Again, this process is interpretable in terms of personal control, if the person giving up cigarettes feels no control over food intake.

(2) Personal control helps us understand why some health promotion programs are unsuccessful.

Why does an otherwise successful program fail to reach some individuals? Perhaps their sense of control over health has been diminished by previous experiences. If the participants have a helpless outlook, the success of a program is blocked. Why do gains made in one setting fail to generalize to another setting? Perhaps the sense of control encouraged in the first setting is confined to that setting.

Community-wide health promotion interventions do not reach all segments of the population equally. Conspicuously absent are members of racial minority groups and lower class men. It is surely not a coincidence that these groups show a diminished sense of control over events in general $[26,28,79,80]$. And precisely these groups show elevated mortality from a variety of illnesses $[81,82]$.

The idea of personal control not only links these disparate facts, but it also prescribes a course of action. Bandura has articulated the role played by control in behavior change [2]. He defines two specific attitudes or beliefs that must be present before people will commit themselves to action, such as participation in programs of health promotion. People must possess or be taught outcome expectancies (that certain behaviors lead to reduced morbidity and mortality) and efficacy expectancies (that they can perform these behaviors). A number of techniques are available to the psychologist for instilling these beliefs in people lacking them [55]. Similarly, mastery training like that conducted by deCharms with respect to academic achievement might prepare undeserved groups for more active participation in health promotion programs [79].

(3) Personal control helps us understand who makes productive use of health facilities and who does not.

It has been estimated that up to $60 \%$ of all visits to a physician are made by people without a significant physical problem [83]. Other people visit 'emergency' rooms for routine medical treatment, and still others who need medical care do not seek it at all. 
The increasing popularity of Health Maintenance Organizations (HMOs) has led to a better understanding of the way people use health care. For a fixed fee per month, the HMO takes care of all the health needs of the subscriber. Once the fee is paid, the traditional barriers to medical treatment are removed, and health professionals confront a variety of people not otherwise encountered in medical practice.

Cummings has distinguished four types of individuals using HMOs: the well; the worried well (somaticizers and potential somaticizers); the asymptomatic sick; and the definitely sick [83, p. 1180]. Traditional health care professionals tend to see the worried well and the definitely sick, since fee-for-service payments keep the other groups away. With such fees removed, HMOs end up with an overwhelming number and variety of patients. What are their individual needs? Perhaps attention to the characteristic personal control beliefs of these individuals might shed light on the services they need.

(4) Personal control suggests ways to tailor health promotion to best reach particular people in particular settings.

Health promotion often looks past the ways that individuals differ from each other. But a program can only succeed if its participants believe that its steps will lead to desired outcomes and that they have the capacity to undertake them (Bandura's outcome and efficacy expectations, respectively). People show great variation in these beliefs [84].

Research in educational settings shows that programs can be tailored to suit students who differ with respect to personal control. Students high in control prefer programs in which they can set their own goals and control their own pace, while those low in control prefer programs with goals already assigned and a pace already imposed [85]. Programs of health promotion could use the same kind of tailoring.

Many health promotion programs employ a variety of techniques, throwing everything imaginable at their target population in the hope that something will reduce the risk factors of concern. In the absence of a theory about how change occurs, this kitchen sink strategy is reasonable. It is also inefficient. And if it works, we learn relatively little, since it is difficult to identify and isolate the active ingredient among the many different strategies.

The notion of personal control promises a better understanding of how health promotion works. We predict that programs work to the degree that they engage personal control. So, it should be possible to predict which programs will be successes and which will be failures. This allows the efficient design of new programs.

(5) Collective control helps us understand why groups of people are amenable to health promotion or not.

Work sites are currently popular settings for programs of disease prevention and health promotion [86]. These programs combat smoking [87], stress [88], obesity [89], and hypertension [90]. Some of these efforts are more successful than others.
Although factors of confidentiality and job security account for some of the variance in the success of work site inventions, the results of the Pennsylvania County Health Improvement Program (CHIP), a community-based multiple risk factor intervention program, make it appear that control is a critical ingredient $[91,92]$. Prevailing labor and management beliefs regarding the degree that group efforts can improve conditions were important determinants of the success or failure of health promotion programs at the work site. The outcomes of these programs depended to an extraordinary degree upon the extent to which labor and management formed a coherent group with a strong sense of personal and collective control.

Collective control cannot exist if there is no collectivity. Before health promotion programs are instituted in work settings (or in any group-schools, neighborhoods, clubs and families), health professionals must be sure that the group has a history of shared purpose. Then, they must ascertain that the group has a sufficient degree of collective control. These assurances form a critical part of the 'company readiness audit' that CHIP has developed to evaluate the readiness of an industry to undertake programs of health promotion [93]. It is only when there are satisfactory responses to these measures that CHIP will proceed to introduce health promotion programs.

(6) Collective control helps us understand why some health promotion staffs are more effective than others.

It is a common belief among health promotion experts that some groups do better jobs than others at community interventions. They are better organized, more resilient in the face of frustration, more successful at recruiting subjects, more skilled at garnering the support of political figures, the media, and granting agencies.

Perhaps most critically, some staffs are better than others at catalyzing the efforts of participantsconvincing them that programs can and will work. These staffs not only possess an abundant sense of personal control but also the capacity to infect others with it. Leadership is no longer as popular an area of concern within psychology as it has been in the past, but the ideas of personal and collective control may provide new impetus to its study.

The efficacious health promotion staff believes in its own ability to control outcomes as well as the ability of others to do so. A large part of its task is to convince community members that both beliefs are warranted. An integral part of the work site process of CHIP is staff assistance in establishing a 'Heart Health Committee' composed of members from labor and managmement [91]. The staff then helps the committee conduct a modest intervention-an Employee Interest Survey of health problems that the employees would like to address. The goals are limited, and designed so that feedback is prompt and (usually) highly favorable. The committee is encouraged to make procedural decisions at every step, and to take the credit (or blame) for the program. These steps cultivate a sense of collective efficacy, and encourage the committee to undertake increasingly ambitious projects. 
(7) There already exist techniques for changing personal control and, by implication, collective control.

Psychologists working within the different traditions of personal control have developed methods of instilling a sense of efficacy. The success of their procedures can be found in classroom, clinic and nursing home studies [94]. Techniques for bolstering control can readily be combined with procedures already used in health promotion programs. Tailoring the programs to reflect differences in personal control within a population can make the resulting interventions more differentiated than current strategies and thus capable of reaching a greater portion of the population.

Communications through the mass media can emphasize the individual's potential for achieving health and avoiding illness. Different messages can be sent to places where they will have the most effect, in accordance with what is known about health-related personal control in different parts of the community. If one wishes to reduce risk factors for coronary disease, messages about exercise may best be directed toward middle-aged men, while suggestions regarding diet may be more appropriately directed toward middle-aged women. Interventions at the work site are undoubtedly more effective when they involve employees in program planning and intervention, thereby encouraging a sense of mastery [91]. The notion of control can be utilized in new and theorybased approaches to target the most pessimistic individuals in the most unresponsive setting. Volunteer organizations can learn to understand the beliefs about personal control of the people they are trying to help. What may facilitate efficacy in one group may undermine it in another.

(8) Theories of control can be melded with the approaches of communication theory and social marketing.

Change at the group level requires techniques that differ from those required for change at the individual level. Psychologists are experts at individual change, but other social scientists may be better at characterizing an audience, choosing a medium to deliver a persuasive communication, designing a message, and facilitating its delivery.

Notions of personal control fit well with the theory and practice of these other fields, which have already assimilated such psychological constructs as selfmanagement [95]. For instance, the Stanford Heart Disease Prevention Program has designed messages that not only persuade recipients that certain behaviors are valuable, but convince them that they have the ability to perform them [96]. Bandura's proposal that personal control can be increased through modeling suggests further interventions [55]. Spokesmen of messages should do more than urge healthy behaviors; they should also exemplify them.

An important link can be established between theories of personal control and theories of the diffusion of innovations. Opinion leadership is a key concept in the study of how innovations (like health behaviors) spread through a community:

the degree to which an individual is able to influence other individuals' attitudes or overt behavior ... Research indi- cates that when the social system is oriented to change, the opinion leaders are quite innovative; but when the norms are opposed to change, the behavior of the leaders also reflects this norm $[97$, p. 27$]$.

Opinion leadership is clearly related to our notions of personal and collective control. Specifying the links between microscopic psychological approaches to change and those of the molar social sciences presents a splendid opportunity to future theorists. Kotarba and Bentley have sketched one form this integration might take, examining participation in health promotion programs as a means for someone to extend a socially-defined and valued identity as a 'well person' [98].

(9) Theories of control suggest ways that groups and societies can be redesigned so that health promotion can occur within them unimpeded.

Personal control refers to specific transactions between a person and his or her world. Contemporary theories of personal control emphasize the setting of behavior, since this is a powerful determinant of what people believe they can do. Personal control is not necessarily identical with reality, but it is realitybased. Thus, the best way to enhance personal control is to redesign settings so that they are responsive to action.

As part-time utopians, we envision a world where cars are always repaired, letters are always answered, lost items are always located, and checks are always in the mailbox. At the same time, we want all crimes to be punished, all errors to lead to failure, and all bluffs to be called. A world where rewards and punishments follow readily from what we do would be a world where fatalism and helplessness were absent.

If we cannot achieve such a world, we suggest that those interested in promoting health look first to the setting in which the intervention will occur. If it is highly centralized, highly directive, and highly capricious, personal and collective control might well be insufficient to warrant intervention at the present time. The prerequisite of a responsive environment must be satisfied first.

(10) Finally, theories of personal control offer a novel model of human nature, one particularly compatible with the present era of health promotion.

Previous visions of human nature have tended to stress either the person or the environment. Theories of personal control transcend this dichotomy and conceive human nature as residing in both. The way in which a person and the environment mesh is a defining characteristic of a person, and personal control is a key construct in conceptualizing this fit which makes us who we are.

Current conceptions attribute health and illness to a complex interplay of biological, psychological, and cultural factors [99]. These views agree with our transactional perspective. Until now, however, programs of health promotion have often been based upon outmoded models of human nature. Some interventions have treated people as passive organisms who can be manipulated into health. Other interventions have treated people as creatures with 
infinitely free will, able to pick and choose their actions solely on the basis of information and moral exhortations. Neither extreme speaks to the needs of real people. But as theories of personal control begin to influence the practice of health promotion, we can expect that interventions will become more sophisticated and more effective.

\section{CONCLUSION}

Matarazzo has called on psychology to meet the challenge posed by behavioral medicine $[100,101]$. How can psychologists contribute to the promotion of health? Perhaps the best way is by articulating the links between behavior and health [76]. We suggest that notions of personal and collective control apply in important ways to health promotion. To date, programs of health promotion have relied on common sense strategies, some of which work and some of which do not. In the future, interventions based on the psychology of control should not only improve the effectiveness of health promotion but also enhance our understanding of why this occurs.

Acknowledgements-We thank these individuals for discussing health promotion with us: Albert Bandura, John Farquhar, Michael R. J. Felix, June Flora, Robert Jeffery, Thomas Lasater, Craig Lefebvre, Maurice Mittelmark, David Murray, Cheryl Perry, Alvan Tarlov, C. Barr Taylor, and Richard Winett. We thank Lisa M. Bossio for editorial advice.

\section{REFERENCES}

1. Kaplan R. M. The connection between clinical health promotion and health status. Am. Psychol. 39, $755-765,1984$.

2. Bandura A. Self-efficacy mechanisms in human agency. Am. Psychol. 37, 122-147, 1982.

3. Adler A. The Practice and Theory of Individual Psychology. Harcourt, Brace \& World, New York, 1927.

4. Erikson E. H. Childhood and Society. Norton, New York, 1952.

5. Hartmann H. Notes on the reality principle. Psychoanal Stud. Child 11, 31-53, 1956.

6. Hendrick I. Instinct and the ego during infancy. Psychoanal Q. 11, 33-58, 1942.

7. Kardiner A. and Spiegel H. War Stress and Neurotic Illness. Hoeber, New York 1947.

8. Murray Explorations in Personality. Oxford University Press, New York, 1938.

9. Lewin K. Principles of Topological Psychology. McGraw-Hill, New York, 1936.

10. Heider F. The Psychology of Interpersonal Relations. Wiley, New York, 1958.

11. Desroche H. The Sociology of Hope. Routledge \& Kegan Paul, London, 1979.

12. Renshon S. A. Psychological Needs and Political Behavior: A Theory of Personality and Political Efficacy. Free Press, New York, 1974.

13. Seeman M. On the meaning of alienation. Am. Sociol. Rev. 24, 783-791, 1959.

14. White R. W. Motivation reconsidered: the concept of competence. Psychol. Rev. 66, 297-333, 1959.

15. Gardner H. The Mind's New Science: A History of the Cognitive Revolution. Basic Books, New York, 1985.

16. Fishbein M. and Ajzen I. Attitudes toward objects as predictors of single and multiple behavioral criteria. Psychol. Rev. 81, 59-74, 1974.
17. Jaceard J. J. Predicting social behavior from personality traits. J. Res. Personal. 7, 358-367, 1974.

18. Bowers K. S. Situations in psychology: an analysis and critique. Psychol. Rev. 80, 307-336, 1973.

19. Endler N. S. and Magnusson D. Toward an interactional theory of personality. Psychol. Bull. 83, 956. 974, 1976.

20. Mischel $W$. On the interface of cognition and personality: Beyond the person-situation debate. Am. Psychol. 34, 740-754, 1979.

21. Janis I. L. Foreword. In The Psychology of Control (Edited by Langer E. J.), pp. 9-11. Sage, Beverly Hills, Calif., 1983.

22. Averill J. Personal control over aversive stimuli and its relationship to stress. Psychol. Bull. 80, 286-303, 1973.

23. Miller S. M. Controllability and human stress: method, evidence, and theory. Behav. Res. Ther. 17 , 287-304, 1979.

24. Thompson S. Will it hurt less if I can control it? A complex answer to a simple question. Psychol. Bull. 90 , 89-101, 1981.

25. Kelley H. H. The processes of causal attribution. Am. Psychol. 28, 107-128, 1973.

26. Rotter J. B. Generalized expectancies for internal versus external control of reinforcement. Psychol. Monogr. 80, 1-28, 1966.

27. Brehm J. W. A Theory of Psychological Reactance. Academic Press, New York, 1966.

28. Seligman M. E. P. Helplessness: On Depression, Development and Death. Freeman, San Francisco, Calif., 1975.

29. Lazarus R. S. and Folkman S. Stress, Appraisal, and Coping. Springer, New York, 1984.

30. Deci E. L. Intrinsic Motivation. Plenum, New York, 1975.

31. McClelland D. C. Power: The Inner Experience. Irvington, New York, 1975.

32. Burger J. M. and Cooper H. M. The desirability of control. Motivation \& Emotion 3, 381-393, 1979.

33. Steiner I. D. Perceived freedom. In Adtances in Experimental Social Psycology (Edited by Berkowitz L.), Vol. 5. Academic Press, New York, 1970.

34. Bandura A. Self-efficacy: toward a unifying theory of behavioral change. Psychol. Rev. 84, 191-215, 1977.

35. deCharms R. Personal Causation. Academic Press, New York, 1968.

36. Langer E. J. Rethinking the role of thought in social interaction. In New Directions in Attribution Research (Edited by Harvey J. H., Ickes W. J. and Kidd R. F.), Vol. 2, pp. 35-58. Erlbaum, Hillsdale, N.J., 1978.

37. Rothbaum F., Weisz J. R. and Snyder S. S. Changing the world and changing the self: a two-process model of perceived control. J. Person. soc. Psychol. 42, 5-37, 1982.

38. Antonovsky A. The sense of coherence as a determinant of health. In Behavioral Health: A Handbook of Health Enhancement and Disease Prevention (Edited by Matarazzo J. D. et al.), pp. 114-129. Wiley, New York, 1984.

39. Kobasa S. C. Stressful life events, personality and health: an inquiry into hardiness. J. Person. soc. Psychol. 37, 1-11, 1979.

40. Lazarus R. S. Positive denial: the case of not facing reality. Psychol. Today 13, 44-60, 1979.

41. Mischel W. Personality and Assessment. Wiley, New York, 1968.

42. Lefcourt H. M. Locus of control for specific goals. In Choice and Perceived Control (Edited by Perlmuter L. C. and Monty R. A.), Pp. 209-220. Erlbaum, Hillsdale, N.J., 1979.

43. Lazarus R. S. Puzzles in the study of daily hassles. J. behav. Med. 7, 375- 389, 1984.

44. Rodin J., Rennert K. and Solomon S. K. Intrinsic 
motivation for control: fact or fiction. In Advances in Environmental Psychology (Edited by Baum A. and Singer J. E.), Vol. 2, pp. 131-148. Erlbaum, Hillsdale, N.J., 1980.

45. Fromm E. Escape from Freedom. Reinhart, New York, 1941.

46. Kelly G. A. The Psychology of Personal Constructs. Norton, New York, 1955.

47. Peterson C. R. and Beach L. R. Man as an intuitive statistician. Psychol. Bull. 68, 29-46, 1967.

48. Nisbett R. E. and Ross L. Human Inference: Strategies and Shortcomings of Social Judgement. Prentice-Hall, Englewood Cliffs, N.J., 1980.

49. Wortman C. B. Some determinants of perceived control. J. Person. soc. Psychol. 31, 282-294, 1975.

50. Langer E. J. The illusion of control. J. Person. soc. Psychol. 32, 311-328, 1975.

51. Alloy L. B. and Abramson L. Y. Judgment of contingency in depressed and nondepressed students: sadder but wiser? J. exp. Psychol. General 108, 441-485, 1979.

52. Lefcourt $H . M$. The function of the illusions of control and freedom. Am. Psychol. 28, 418-425, 1973.

53. DeMonbreun B. G. and Craighead W. E. Distortion of perception and recall of positive and neutral feed. back in depression. Cognit. Ther. Res. 1, 311-320, 1979.

54. Campbell D. T. and Fiske D. W. Convergent and discriminant validation by the multitrait-multimethod matrix. Psychol. Bull. 56, 81-105, 1959.

55. Bandura A. Social Foundations of Thought and Action: A Social Cognitive Theory. Prentice-Hall, Englewood Cliffs, N.J., 1986.

56. Rappaport J. Community Psychology: Values, Research and Action. Holt, Rinehart \& Winston, New York, 1977.

57. Peterson C. and Seligman M. E. P. Explanatory style and illness. J. Personal. 55, 237-265, 1987.

58. Peterson C., Seligman M. E. P. and Vaillant G. E. Pessimistic explanatory style is a risk factor for physical illness: a thirty-five year longitudinal study. $J$. Person. soc. Psychol. 55, 23-27, 1977.

59. Hackett T. P. and Cassem N. H. Development of a quantitative rating scale to assess denial. J. psychosom. Res 18, 93-100, 1974.

60. Jemmott J. B. and Locke S. E. Psychosocial factors, immunologic mediation and human susceptibility to infectious diseases: how much do we know? Psychol. Bull. 95, 78-108, 1984.

61. Langer E. J. and Rodin J. The effects of choice and enhanced personal responsibility for the aged: a field experiment in an institutional setting. J. Person. soc. Psychol. 34, 191-198, 1976.

62. McClelland D. C. and Jemmott J. B. Power motivation, stress and physical illness. J. Human Stress 6, 6-15, 1980.

63. Seeman $M$. and Seeman T. E. Health behavior and personal autonomy: longitudinal study of the sense of control in illness. J. Hlth soc. Behav. 24, 144-160, 1983.

64. Strickland B. R. Internal-external expectancies and health-related behaviors. J. consult. clin. Psychol. 46, 1192-1211, 1978.

65. Wallston K. A. and Wallston B. S. Who is responsible for your health? the construct of health locus of control. In Social Psychology of Health and Illness (Edited by Sanders G. S. and Suls J.), pp. 65-95. Erlbaum, Hillsdale, N.J., 1982.

66. Zeigler M. and Reid D. W. Correlates of changes in desired control scores and in life satisfaction scores among elderly persons. Int. J. Aging Human Devl. 16, 135-146, 1983.

67. Rodin J., Timko C. and Anderson S. The construct of control. In Annual Review of Gerontology and Geri- atrics (Edited by Lawton P. and Maddox G.), Vol. 5. Springer, New York, 1985.

68. Cobb S. Social support as a moderator of life stress. Psychosom. Med. 38, 300-314, 1976.

69. Kaplan G. A. and Camacho T. Perceived health and mortality: a nine-year follow-up of the human population laboratory cohort. Am. J. Epidem. 117, 292-304, 1983.

70. Mossey J. M. and Shapiro E. Self-rated health: a predictor of mortality among the elderly. Am. J. publ. Hlth 72, 800-808, 1980.

71. Condiotte M. M. and Lichtenstein E. Self-efficacy and relapse in smoking cessation programs. $J$. consult. clin. Psychol. 49, 648-658, 1981.

72. O'Leary A. Self-efficacy and health. Behav. Res. Ther. 23, 437-451, 1985.

73. Taylor R. B., Denham J. R. and Ureda J. W. Health Promotion: Principles and Clinical Applications. Appleton-Century-Crofts, Norwalk, Conn.. 1982.

74. Belloc N. B. Relationship of health practices and mortality. Pretent. Med. 2, 67-81, 1973.

75. Belloc N. B. and Breslow L. Relationship of physical health status and health practices. Prevent. Med. 1, 409-421, 1972.

76. Singer J. E. and Krantz D. S. Perspectives on the interface between psychology and public health. Am. Psychol. 37, 955-960, 1982.

77. Wadden T. A. and Brownell K. D. The development and modifications of dietary practices in individuals, groups, and large populations. In Behavioural Health: A Handbook of Health Enhancement and Disease Prevention (Edited by Matarazzo J. D. et al.), pp. 608-631. Wiley, New York, 1984.

78. Lefebvre R. C. Primary prevention of coronary heart disease: a review of multifactor prevention trials. In Progress in Behavior Modification (Edited by Hersen M., Eiser R. M. and Miller P. M.), Vol. 21. Academic Press, New York, 1986.

79. deCharms R. Enhancing Motivation: Change in the Classroom. Irvington, New York, 1976.

80. Winter D. G. The Power Motive. Free Press, New York, 1973.

81. Syme S. L. and Berkman L. F. Social class, susceptibility, and sickness. Am. J. Epidem. 104, 1-8, 1976.

82. Wingard D. L., Berkman L. F. and Brand R. J. A multivariate analysis of health-related practices. Am. J. Epidem. 116, 765-755, 1982.

83. Cummings N. A. The Health Maintenance Organization. In Behavioral Health: A Handbook of Health Enhancement and Disease Prevention (Edited by Matarazzo J. D. et al.), pp. 1179-1186. Wiley, New York, 1984.

84. Becker M. H. (Ed.) The Health Belief Model and Personal Health Behavior. Slack, Thorofare, N.J., 1974.

85. Forward J. R., Wells K., Canter R. and Waggoner $\mathbf{M}$. Teacher control strategies and choice of educational objectives among college students. J. Educ. Psychol. 67, 757-763, 1975.

86. Nathan P. E. The worksite as a setting for health promotion and positive lifestyle change. In Behavioral Health: A Handbook of Health Enhancement and Disease Prevention (Edited by Matarazzo J. D. el al.), pp. 1061-1063. Wiley, New York, 1984.

87. Orleans C. S. and Shipley R. H. Worksite smoking cessation initiatives: review and recommendations. Addict. Behav. 7, 1-16, 1982.

88. Peters R. K., Benson H. and Porter D. Daily relaxation response breaks in a working population: 1 . Effects of self-reported measures of health, performance and well-being. Am. J. publ. Hlth 67, 946-953, 1977. 
89. Stunkard A. J, and Brownell K. D. Work-site treatment of obesity. Am. J. Psychiat. 137, 252-253, 1980.

90. Alderman M. H. and Schoenbaum E. E. Detection and treatment of hypertension at the worksite. New Engl. J. Med. 293, 65-68, 1975.

91. Felix M. R. J., Stunkard A. J., Cohen R. Y. and Cooley N. B. Health promotion at the worksite: I. A process for establishing programs. Prevent. Med. 14, 99-108, 1985.

92. Stunkard A. J., Felix M. R. J. and Cohen R. Y. Mobilizing a community to promote health: The Pennsylvania County Health Improvement Program (CHIP). In Prevention in Health Psychalogy (Edited by Rosen J. C. and Solomon L. J.), University Press of New England, Hanover, N.H., 1985.

93. Stunkard A. J. and Felix M. R. J. Developing chambers of commerce as vehicles for health promotion at the work site. Unpublished manuscript, University of Pennsylvania, 1985 .

94. Antaki C. and Brewin C. (Eds) Attributions and Psychological Change: A Guide to the Use of Attribution
Theory in the Clinic and the Classroom. Academic Press, London, 1982.

95. Solomon D. S. and Maccoby N. Communication as a model for health enhancement. In Behovioral Health: A Handbook of Health Enhancement and Disease Prevention (Edited by Matarazzo D. et al.), pp. 209-221. Wiley, New York, 1984.

96. Farquhar J. Personal communication, 1985.

97. Rogers E. M. Diffusion of Innovations, 3rd edn. Free Press, New York, 1983.

98. Kotarba J. A. and Bentley P. Workplace, wellness, participation and the becoming of self. Soc. Sci. Med. 26, 551-558, 1988.

99. Engel G. L. The clinical application of the biopsychosocial model. Am. J. Psychiat. 137, 535-544, 1980.

100. Matarazzo J. D. Behavioral health and behavioral medicine: frontiers for a new health psychology. Am. Psychol. 35, 807-817, 1980.

101. Matarazzo J. D. Behavioral health's challenge to academic, scientific and professional psychology. Am. Psychol. 37, 1-14, 1982. 